\title{
Protective Effect of Resveratrol against Oxidation Stress Induced by 2-Nitropropane in Rat Liver
}

\author{
Maura Lodovici, Elisabetta Bigagli, Cristina Luceri, Elena M. Manni, Mohamed Zaid
}

Department of Pharmacology, University of Florence, Florence, Italy.

Email: maura.lodovici@unifi.it

Received March 29 $9^{\text {th }}, 2011$; revised April 25 ${ }^{\text {th }}, 2011$; accepted May $17^{\text {th }}, 2011$.

\begin{abstract}
We investigated the effect of resveratrol on oxidation damage and variation of antioxidant defences induced by 2-nitropropane (2-NP) in rat liver. One group of five rats was given resveratrol (50 $\mathrm{mg} / \mathrm{kg} / \mathrm{d}$ body weight) in the diet until the end of the experiment. After 14 days, 2-NP (100 mg/kg) was injected i.p. into two groups of animals (2-NP + Res and 2-NP groups) while control animals were treated with vehicle alone. Animals were killed by decapitation $15 \mathrm{~h}$ after 2-NP injection. The levels of 8-oxo-7,8-dihydro-2'-deoxyguanosine (8-oxodGuo) were significantly increased by 2-NP injection, but resveratrol restored 8-oxodGuo to levels similar to those measured in controls. Superoxide dismutase (SOD) and xanthine oxidase $(X O)$ activities in the liver were significantly increased by 2-NP, but were similar to those found in the group treated with resveratrol and 2-NP (2-NP + Res). We also observed that 2-NP injection significantly reduced GSH/GSSG ratio in the liver and this change was partially reversed by resveratrol treatment. Moreover, an increased $(p=0.06)$ expression of the oxoguanine glycosylase (OGG1) gene was found in 2-NP rats, whereas pre-treatment with resveratrol restored OGG1 expression to control levels. An up-regulation of caspase-3 was also observed in 2-NP group, but resveratrol significantly reduced the activation of caspase-3. An inverse correlation was found between GSH/GSSG and 8-oxodGuo in the 2-NP group. On the contrary, 8-oxodGuo levels, GSH/GSSG ratio, $X O$ and SOD activities in the colon mucosa of 2-NP rats were similar to those of controls confirming that the colon is not a target of oxidation damage 2-NP induced. In conclusion, our results indicate that oxidative DNA damage and apoptosis are the main mechanisms of cell death in a model of chemically induced severe acute hepatic injury and in this early stage of damage pharmacological doses of resveratrol can ameliorate hepatic oxidation damage by its antioxidant and scavenging properties through a reduction of XO activity, a partial restoration of GSH/GSSG ratio in addition to its capacity to inhibit apoptosis.
\end{abstract}

Keywords: 2-Nitropropane, 8-Oxodguo, lipoperoxidation, MDA, XO, SOD, Resveratrol, Apoptosis

\section{Introduction}

It is well documented that DNA damage induced by reactive oxygen species (ROS) plays an important role in aging and in a number of human pathological processes, such as chronic inflammation, atherosclerosis, diabetes, ischemia-reperfusion injury and cancer [1-5]. Resveratrol is a natural phenolic compound with free radical scavenging and antioxidant properties [6-9]. Many studies have demonstrated the anti-inflammatory and anticancer effects of resveratrol in various organs [10-12]. In addition, Harikumar and Aggarwal [13] reported that resveratrol is capable of binding to numerous macromolecules involved in cell function, such as multidrug resistance proteins, topoisomerase II, aromatase, DNA polymerase, estrogen receptors and tubulin. Resveratrol can also activate various transcription factors (NF-kB, STAT3, $\beta$-catenin and PPAR- $\gamma$ ), inhibit many protein kinases, induce antioxidant enzymes [13] and reduce alterations in the protein expression of mitochondria-mediated apoptosis markers [14]. Recently, Tunali-Akbay et al. [15] found that resveratrol protects against methotrexateinduced hepatic injury in rats by reversing the oxidative toxic damage. In addition, has been reported that resveratrol is able to suppress oxidative stress and inflammatory response in rat hepatocarcinogenesis induced by diethylnitrosamine [16].

A specific nitroalkane, 2-nitropropane (2-NP), used as a constituent of paints and inks and present in tobacco smoke, can cause hepatic damage in humans and animals $[17,18]$. The mechanism by which 2-NP induces hepatoxicity is not clearly defined, but since many studies 
have demonstrated its effect as a potent inducer of oxidative DNA damage in liver tissue, its toxicity is interpreted as a consequence of ROS generation $[18,19]$. Thus, 2-NP has been widely used as a model compound for studies of oxidation damage in the liver of rodents [20-22].

On the basis of these considerations, the present studies were carried out to determine the effects of resveratrol on 2-NP-induced oxidative stress and apoptotic changes in the rat liver.

\section{Materials and Methods}

\subsection{Animals and Treatments}

All experiments were carried out in accordance with the European Communities Council Directive of 24 November 1986 (86/609/EEC) for experimental animal care.

Male Fisher 344 rats $(180-200$ g) were purchased from Nossan (Milan, Italy). After their arrival from the supplier, 15 animals were quarantined for 1 week and fed standard lab chow and water, ad libitum. The rats were then randomly divided into three groups of 5 rats each. One group (2-NP + Res) was given resveratrol (50 $\mathrm{mg} / \mathrm{kg} / \mathrm{d}$ body weight) in the diet until the end of the experiment. The dose of resveratrol was selected by taking into account the safety of this compound in animal studies [23] and based on previously reported chemopreventive doses of resveratrol in rodents [24]. A second group was administered only 2-NP and the third group served as control (C). Taking into account that approximately 15 $\mathrm{g}$ of diet were consumed by each rat every day, we added resveratrol in the diet $(600 \mathrm{ppm})$ in order to reach a dose of $50 \mathrm{mg} / \mathrm{kg} /$ day. After 14 days, $100 \mathrm{mg} / \mathrm{kg}$ of $2-\mathrm{NP}$ in saline supplemented with $0.1 \%$ Tween 80 was injected i.p. into 2 groups of animals while the control group (C) was treated with the vehicle alone. Animals of all 3 groups were killed by decapitation $15 \mathrm{~h}$ after 2-NP injection. The liver and colon were excised and frozen at $-80^{\circ} \mathrm{C}$. Liver and colon tissues were homogenized in 50 $\mathrm{mM}$ phosphate buffered solution (PBS) containing $0.1 \mathrm{M}$ dithiothreitol and then centrifuged at $4{ }^{\circ} \mathrm{C}$ for $20 \mathrm{~min}$ at $2000 \times$ g. Pellets were used for 8-oxo-7,8-dihydro-2'deoxyguanosine (8-oxodGuo) determination, while malonyldialdehyde (MDA), protein carbonyl residues, superoxide dismutase (SOD), xanthine oxidase (XO) were measured in the liver and colon mucosa supernatants. In addition, in the liver supernatant reduced (GSH) and oxidized glutathione (GSSG), were also measured.

\subsection{Materials}

2-NP, resveratrol and all chemicals were purchased from Sigma, Milan, Italy. HPLC Shimadzu (10 AD). Cou- lochem II electrochemical detector (ESA). UV (Perkin Elmer) detector.

\subsection{8-Oxodguo Assay}

Liver pellets were re-suspended and DNA was isolated with the method recommended by ESCODD group [25]. Purified DNA was hydrolysed with P1 nuclease (14 IU) and alkaline phosphatase (10 IU). The hydrolysed mixture was filtered using Micropure-EZ enzyme remover (Amicon, MA, USA) and $50 \mu \mathrm{l}$ were injected into an HPLC apparatus. The nucleosides were separated using a C18 reverse-phase column (Supelco, $5 \mu \mathrm{m}$, I.D. $0.46 \times$ $25 \mathrm{~cm}$ ). The 8-oxodGuo and $2 \mathrm{dG}$ levels in DNA were measured using an ESA Coulochem II electrochemical detector in line with a UV detector as previously described [26].

\subsection{Carbonyl Residues Assessment}

Carbonyl residues were determined by the method of Correa-Salde and Albesa [27]. Liver supernatant (0.35 $\mathrm{ml}$ ) was treated for $1 \mathrm{~h}$ with $1 \mathrm{ml}$ of $0.1 \%$ dinitrophenylhydrazine in $2 \mathrm{M} \mathrm{HCl}$ and precipitated with $10 \%$ trichloroacetic acid before being centrifuged for $20 \mathrm{~min}$ at $10,000 \mathrm{x}$ g. The pellets were extracted with $1 \mathrm{ml}$ of an ethanol:ethyl acetate mixture $(1: 1)$ three times and then dissolved in $2 \mathrm{ml}$ of $6 \mathrm{M}$ guanidine $\mathrm{HCl}$ in $20 \mathrm{mM}$ potassium phosphate buffer (PBS) $\mathrm{pH}$ 7.5. The solutions were incubated at $37^{\circ} \mathrm{C}$ for $30 \mathrm{~min}$ and insoluble debris was removed by centrifugation. The absorbance was measured at $364 \mathrm{~nm}$.

\subsection{MDA Determination}

MDA was determined after derivatization with 2,4-dinitrophenylhydrazine (DNPH) as described by Mateos et al. [28]. Briefly, $50 \mu \mathrm{l}$ of $6 \mathrm{M} \mathrm{NaOH}$ were added to an aliquot of $500 \mu \mathrm{l}$ of liver supernatant. Alkaline hydrolysis of protein bound MDA was achieved by incubating this mixture in a $60^{\circ} \mathrm{C}$ water bath for $30 \mathrm{~min}$ and protein precipitated with $250 \mu$ l of $30 \%(\mathrm{v} / \mathrm{v})$ trichloroacetic acid. A $250 \mu 1$ volume of supernatant was mixed with $25 \mu 1$ of 5 $\mathrm{mM}$ DNPH in $2 \mathrm{M}$ hydrochloric acid. Finally, this reaction mixture was incubated for $30 \mathrm{~min}$ at room temperature protected from light. An aliquot of $100 \mu \mathrm{l}$ was injected into a Shimadzu LC-10AD HPLC system with a Waters Spherisorb RP-18 column $(4.6 \mathrm{~mm} \times 150 \mathrm{~mm}$, ODS 25 um, Supelco).

Samples were eluted with a mixture of $0.2 \%(\mathrm{v} / \mathrm{v})$ acetic acid and acetonitrile $(62: 38, \mathrm{v} / \mathrm{v})$ at a flow rate of 0.8 $\mathrm{ml} / \mathrm{min}$. Chromatograms were acquired at $310 \mathrm{~nm}$. The calibration curve, prepared by diluting a standard solution of tetraethoxypropane (TEP), was reported in Figure 1. 


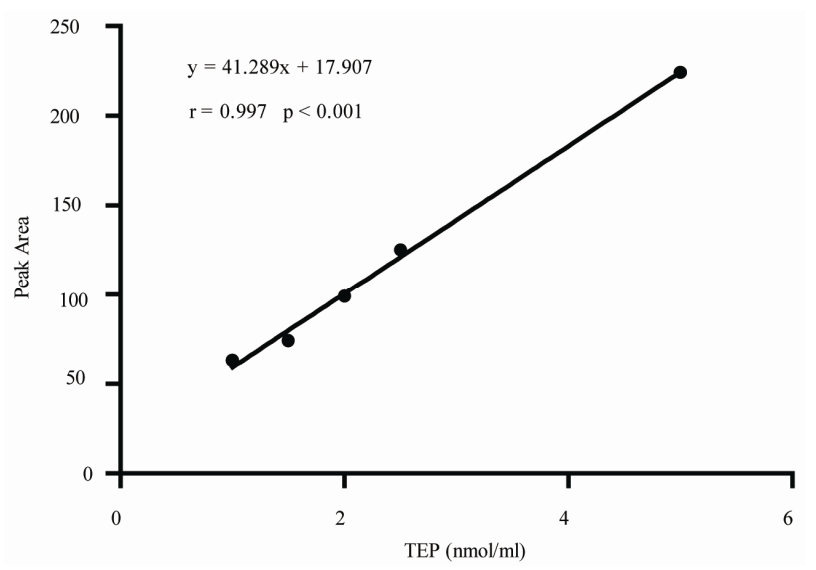

Figure 1. Calibration curve of MDA.

\subsection{SOD Activity}

SOD was determined in the liver supernatant using the nitroblue tetrazolium (NBT) reaction [29]. The reaction mixture, containing $0.2 \mathrm{ml}$ of liver supernatant, $2.4 \mathrm{ml}$ of $50 \mathrm{mM} \mathrm{Na} \mathrm{CO}_{3}, 0.1 \mathrm{ml}$ of $3 \mathrm{mM}$ EDTA, $0.1 \mathrm{ml}$ of $3 \mathrm{mM}$ xanthine, $0.1 \mathrm{ml}$ of $0.8 \mathrm{mM}$ NBT and $0.1 \mathrm{ml}$ of XO (140 $\mathrm{mU} / \mathrm{ml}$ initial concentration), was incubated for $30 \mathrm{~min}$ at $24^{\circ} \mathrm{C}$. The inhibition of NBT reduction in each sample was determined spectrophotometrically at $470 \mathrm{~nm}$. SOD content, expressed as U/mg protein, was evaluated by relating to inhibition by the SOD standard measured at the same time.

\subsection{XO Activity}

$\mathrm{XO}$ was determined in the liver supernatant according to Corte and Stirpe [30]. XO activity, expressed as U/mg protein, was assayed by measuring uric acid production at $280 \mathrm{~nm}$.

\subsection{Determination of GSH and GSSG}

The procedure was performed following the method by Cereser et al. [31] with few modifications. Briefly, 100 $\mu 1$ of liver supernatant were diluted by addition of 500 $\mathrm{mM}$ sodium phosphate $\mathrm{pH} 7 ; 100 \mu \mathrm{l}$ of this solution was mixed with $100 \mu \mathrm{l}$ ortho-pthalaldehyde (OPA) $(5 \mathrm{mg} / \mathrm{ml})$ and $100 \mu \mathrm{l}$ was injected into an HPLC system to determine reduced GSH; total glutathione (GSHt) was evaluated by performing a reduction step of GSSG with dithiotreitol. The GSSG concentration was obtained by subtraction of the GSH from the GSHt. Chromatography of GSH and GSHt after their derivatization with OPA was accomplished using isocratic elution in a Discovery C18 $(150 \mathrm{~mm} \times 4 \mathrm{~mm}$ i.d.) $5 \mu \mathrm{m}$ analytical column (Supelco, USA) at $37^{\circ} \mathrm{C}$. The mobile phase consisted of $8 \%$ acetonitrile in $50 \mathrm{mM}$ sodium acetate $\mathrm{pH}$ 6.2. The flow rate was set at $1 \mathrm{ml} / \mathrm{min}$. An optimum response of the fluorescent derivate was observed when the excitation and emission wavelengths in the detector were set at 350 and $420 \mathrm{~nm}$, respectively.

\subsection{Oxoguanine Glycosylase (OGG 1) mRNA Levels in the Liver}

Total liver RNA was extracted using the RNeasy Midi kit with DNase step (Qiagen, Milan, Italy), according to the manufacturer's instructions. For first-strand cDNA synthesis, $1 \mathrm{mg}$ of total RNA from each sample was reverse-transcribed using 100 units of RT Super-Script II (Life Technologies, San Giuliano, Milan, Italy) and 1X random hexamers (Roche Diagnostics, Monza, Italy). The primers used were: OGG1 (NM_030870) F 5'-CAC TTC CAA AGT GTG GCT CA-3; R 5'-CAT AAG AGG CCA CTC GAA GC-3' (346 bp); $\beta$-actin F 5'-ACC ACA GCT GAC AGG GAA ATC G-3'; R 5'-AGA GGT CTT TAC GGA TGT CAA CG-3' (281 bp).

The PCR reactions were carried out in a $25 \mu \mathrm{L}$ volume containing 1X PCR buffer, $1.2 \mathrm{mmol} / \mathrm{L} \mathrm{MgCl}_{2}, 0.5$ $\mathrm{mmol} / \mathrm{L}$ dNTPs, $1.6 \mu \mathrm{mol} / \mathrm{L}$ of OGG1 primers, 0.04 $\mu \mathrm{mol} / \mathrm{L}$ of the $\mathrm{b}$-actin primers and $1.25 \mathrm{U}$ of Taq polymerase (Sigma-Aldrich, Italy). The PCR conditions were: $95^{\circ} \mathrm{C}$ for $7 \mathrm{~min}$ and then 35 cycles at $95^{\circ} \mathrm{C}$ for $30 \mathrm{sec}$, $60^{\circ} \mathrm{C}$ for $30 \mathrm{sec}$ and $72^{\circ} \mathrm{C}$ for $55 \mathrm{sec}$. PCRs were performed in a Perkin Elmer 9700 thermal cycler (Perkin Elmer, Foster City, CA, USA). The PCR products were separated on $1.6 \%$ agarose gel and visualized by ethidium bromide staining. Gel images were captured by a digital photocamera (UviDoc) and the intensity of the bands was analysed with Quantity-One software (BioRad, Segrate, Milan, Italy). The relative amount of mRNA in the samples was normalised using b-actin co-amplified as internal standard [32].

\subsection{Western-Blot}

Liver samples were homogenized in lysis buffer of the following composition (in $\mathrm{mM}$ ): $50 \mathrm{Tris} \cdot \mathrm{HCl} \mathrm{pH} \mathrm{7.5,1}$ EDTA, $150 \mathrm{NaCl}, 1 \mathrm{Na}_{3} \mathrm{VO}_{4}, 10 \mathrm{NaF}$ and complete protease inhibitor cocktail tablet (Sigma-Aldrich, St. Louis, MO, USA). The homogenate was centrifuged $(1000 \times \mathrm{g})$ for $10 \mathrm{~min}$ at $4^{\circ} \mathrm{C}$ to remove cell debris. Proteins were then separated on a $12 \%$ (w/vol) SDSPAGE, transferred to PVDF membranes, blocked with Blocker Non-Fat Dry Milk (Bio-Rad, Richmond, CA) and probed with mouse anti-rabbit caspase-3 polyclonal antibodies (1:1000 dilution; St. Cruz Biotechnology Inc., CA, USA) or with polyclonal anti-rabbit glyceraldehyde3-phosphate dehydrogenase (GAPDH; 1:1000 dilution; Sigma-Aldrich, St. Louis, MO, USA) overnight at $4^{\circ} \mathrm{C}$. After extensive washings, a monoclonal goat anti-rabbit peroxidase conjugated antibody was added (1:10000 dilution; Sigma-Aldrich, St. Louis, MO, USA) and immu- 


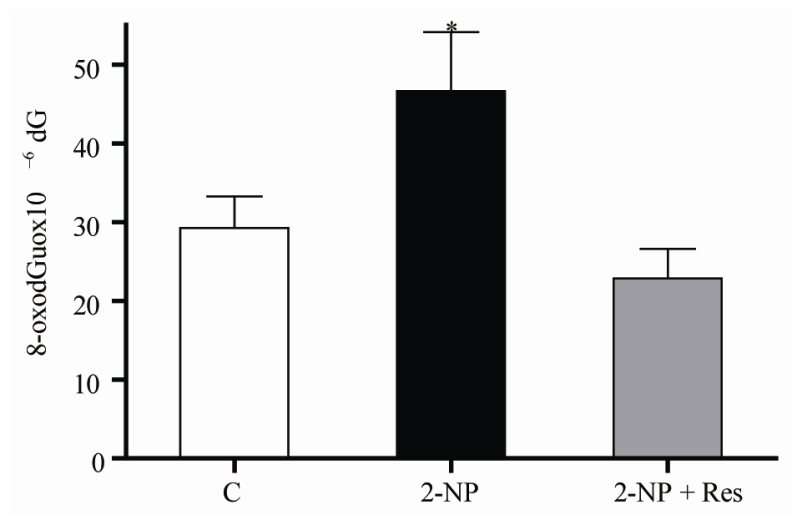

Figure 2. Levels of 8-oxodGuo in the liver DNA of control rats $(\mathrm{C})$, rats treated with $2-\mathrm{NP}$ and those administered 2$\mathrm{NP}$ and resveratrol (2-NP + Res). Data are expressed as means \pm S.E.M; $n=5$ in each group. ${ }^{*} \mathbf{p}<0.05$ vs. C.

nodetected bands were visualized by ECL. Densitometric analysis of autoradiographic bands referred to GAPDH expression, taking into account the size and area of the band (Scion software Image Corp).

\subsection{Statistical Analysis}

Parametric variables were compared using the t-test. Correlations were performed using linear regression analysis, and the significance level was considered as $\mathrm{p}<$ 0.05 . The statistical analysis was carried out using the Stata statistical package (Stata, Collage Station, TX).

\section{Results}

To evaluate the effect of resveratrol on oxidation damage in the rat liver, we used 2-NP to induce oxidative DNA damage.

Administration by i.p. of $100 \mathrm{mg} / \mathrm{kg}$ 2-NP generated ROS and considerably increased 8-oxodGuo in the rat liver DNA, $15 \mathrm{~h}$ after injection (Figure 2). Pre-treatment of rats with resveratrol $(50 \mathrm{mg} / \mathrm{kg} / \mathrm{d})$ for 14 days before 2-NP administration restored 8-oxodGuo in DNA to levels similar to those of controls (Figure 2). Although the average protein oxidation measured as carbonyl residues was not significantly modified by 2-NP injection (Table 1), a correlation between carbonyl residues and 8-oxodGuo levels in the liver of rats treated with 2-NP was found (Figure 3).

2-NP induced an increase (about 2.5-fold) in SOD activity and a slight, but significant increase in XO activity, a pro-oxidant enzyme; however, in the group treated with resveratrol, SOD and XO levels were similar to controls (Table 1). On the contrary, lipoperoxidation, measured as MDA levels, was similar in the three groups (Table 1). An inverse correlation existed between MDA and SOD activity in rats from 2-NP group (Figure 4).

We examined whether 2-NP injection affected the ex-
Table 1. SOD and XO activities, carbonyl residues in proteins, MDA and OGG1 expression levels in the liver of control rats $(\mathrm{C})$, rats treated with 2-nitropropane (2-NP) and in those administered 2-nitropropane and resveratrol (2-NP + Res).

\begin{tabular}{cccc}
\hline & C & 2-NP & 2-NP + Res \\
\hline SOD (U/mg) & $4.2 \pm 1.3$ & $10.3 \pm 1.9^{*}$ & $5.3 \pm 1.5$ \\
XO (U/mg) & $2.3 \pm 0.38$ & $3.6 \pm 0.41^{*}$ & $2.8 \pm 0.75$ \\
Carbonyl residues & $0.34 \pm 0.03$ & $0.41 \pm 0.12$ & $0.35 \pm 0.02$ \\
(nmol/mg) & $0.14 \pm 0.01$ & $0.10 \pm 0.01$ & $0.13 \pm 0.01$ \\
MDA ( $\mu \mathrm{M})$ & $0.72 \pm 0.16$ & $1.18 \pm 0.07^{\$}$ & $0.99 \pm 0.35$ \\
OGG1/b-actin expres- & 0.99 \\
\hline sion (Arbitrary Unit)
\end{tabular}

Data are expressed as means \pm S.E.M. $n=5$ in each group; ${ }^{*} p<0.05 \mathrm{vs}$ $\mathrm{C} ;{ }^{\$} \mathrm{p}=\mathbf{0 . 0 6 0}$ vs. $\mathrm{C}$.

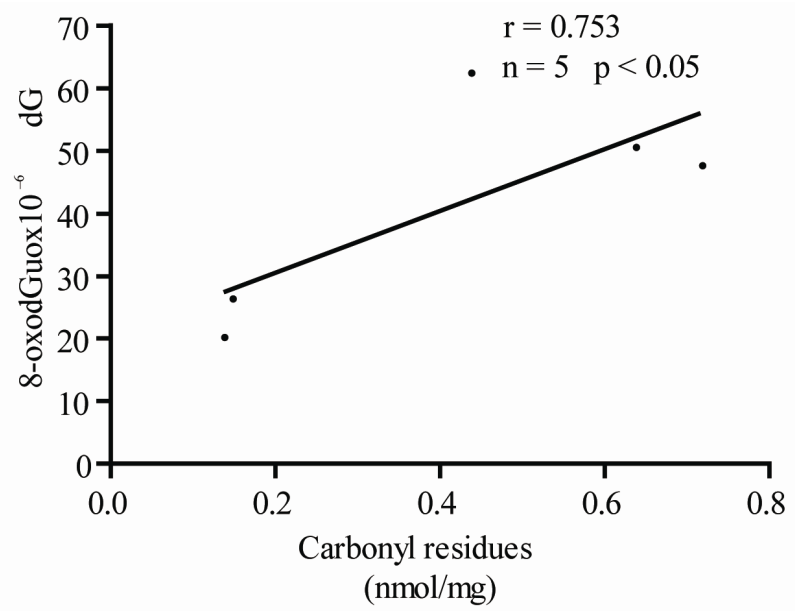

Figure 3. Correlation between carbonyl residues and 8oxodGuo levels in liver of 2-NP rat group.

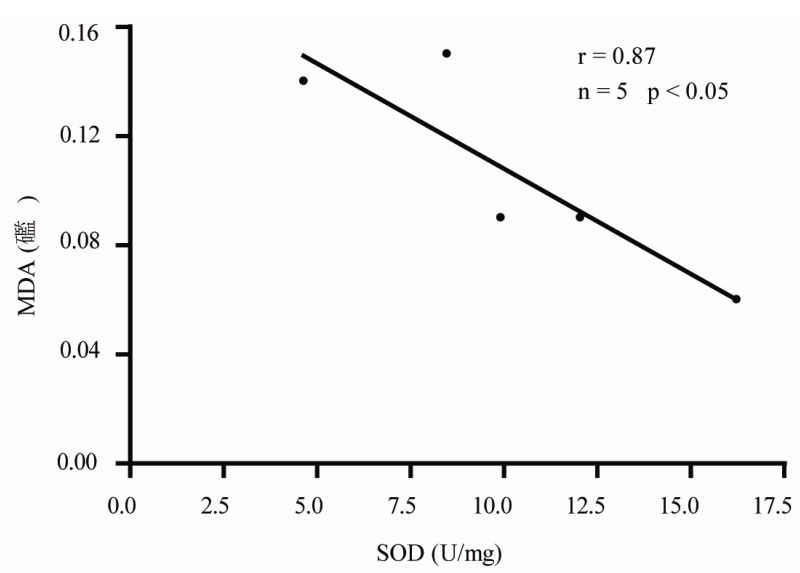

Figure 4. Correlation between MDA levels and SOD activity in liver of rats treated with 2-NP.

pression of the 8-oxoguanine-DNA glycosylase (OGG-1) which catalyses the removal of mutagenic 8-oxo-7,8-dihydroguanine from DNA. We observed a borderline significant increased expression of the OGG1 gene in the rat 


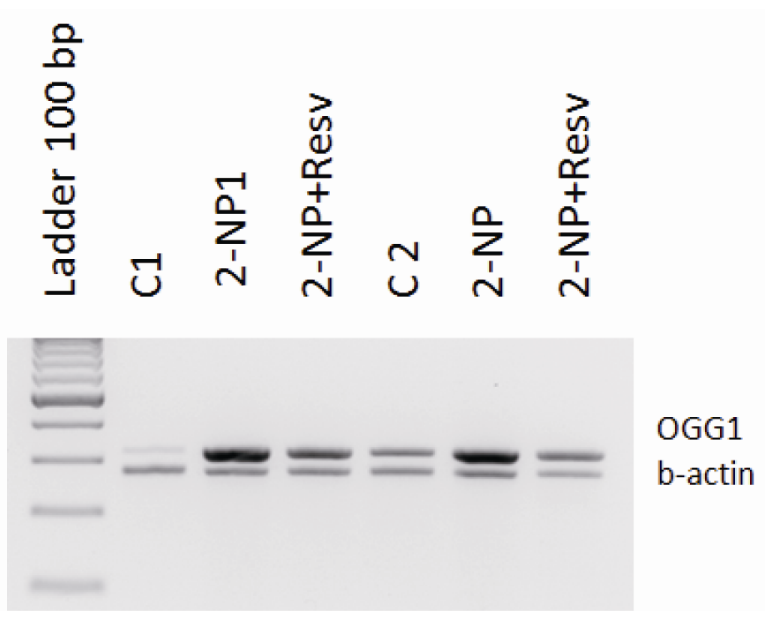

Figure 5. Example of the analysis of OGG1 gene expression by semi-quantitative RT-PCR, using total RNA extracted from livers of controls $(C, n=2)$, treated with $2-N P(n=2)$ and those administered 2-NP and resveratrol (2-NP + Res, $\mathbf{n}=2$ ) and $\mathbf{b}$-actin as an internal standard.

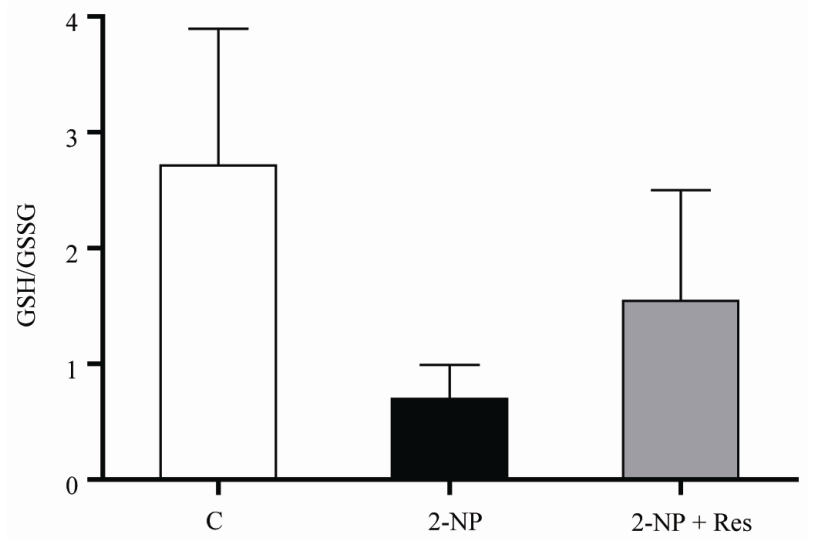

Figure 6. GSH/GSSG ratio in the liver DNA of control rats (C), rats treated with 2-NP and those administered 2-NP and resveratrol (2-NP + Res).

liver of 2-NP group ( $\mathrm{p}=0.06)$ whereas, rats pre-treated with resveratrol showed a hepatic OGG1 expression similar to that observed in controls (Table 1 and Figure 5).

Treatment with 2-NP also significantly reduced GSH/ GSSG ratio (75\%) in comparison to controls and this change was partially reversed by resveratrol (Figure 6). An inverse correlation existed between the GSH/GSSG ratio and 8-oxodGuo in 2-NP group (Figure 7). Figure 8 shows Western blot analysis for the 2-NP induced alterations and preventive response of resveratrol on the expression of specific marker protein (activated caspase-3) of apoptosis in the rat liver. Animals responded to 2-NP $(100 \mathrm{mg} / \mathrm{kg}$ ) injection by up-regulating the activation of caspase-3 (about 40-fold) in comparison to controls.

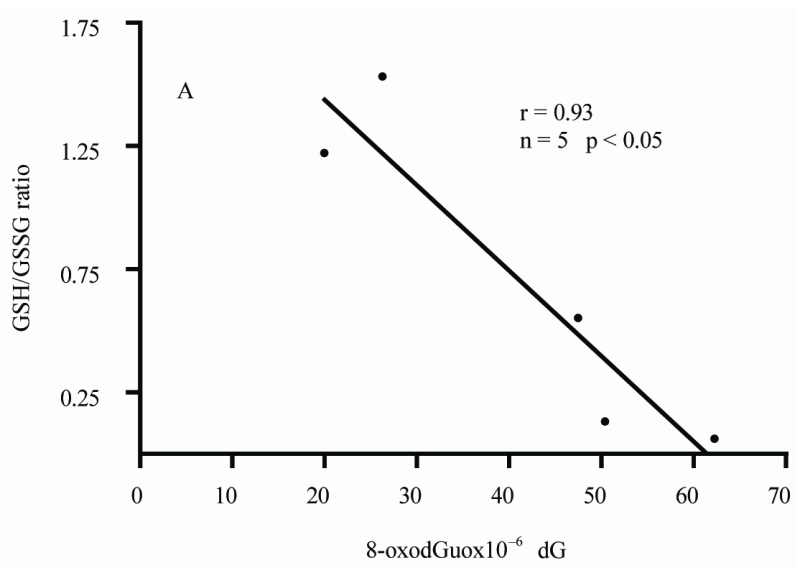

Figure 7. Correlation between GSH/GSSG ratio and 8oxodGuo levels in the liver of rats treated with 2-NP.
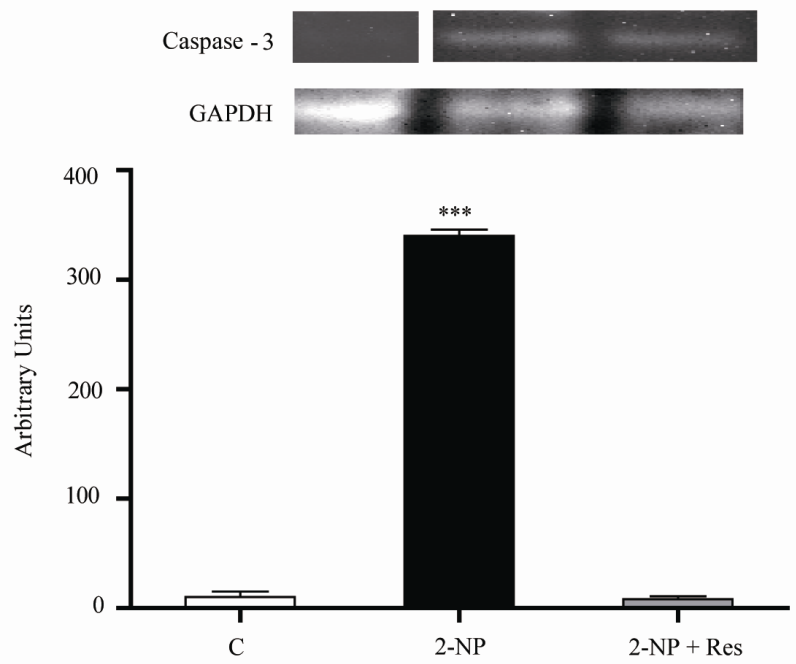

Figure 8. Levels of caspase- 3 in the liver of control rats (C), rats treated with $2-\mathrm{NP}$ and those administered 2-NP and resveratrol (2-NP + Res).

Pre-treatment with resveratrol $(50 \mathrm{mg} / \mathrm{kg} / \mathrm{d})$ for 14 days before the 2-NP injection significantly reduced the activation of caspase-3 (Figure 8).

We saw no oxidation damage on the colon mucosa after 2-NP, in fact, all measured markers of oxidative stress and antioxidant response were similar to those of controls (Table 2).

\section{Discussions}

Resveratrol is a phenolic compound with free-radical scavenging and antioxidant properties [8,9]. Our data show that treatment with resveratrol before 2-NP injection significantly reduces oxidative stress and apoptosis in the liver of rats.

These results are consistent with previous studies demonstrating resveratrol does prevent the increased of 
Table 2. Levels of 8-oxodGuo, SOD and XO activities, carbonyl residues in proteins and MDA in the colon mucosa of control rats $(\mathrm{C})$, rats treated with 2-nitropropane (2-NP) and in those administered 2-nitropropane and resveratrol (2-NP + Res).

\begin{tabular}{cccc}
\hline & C & 2-NP & 2-NP + Res \\
\hline & & & \\
8-oxodGuo/106 dG & $9.2 \pm 1.4$ & $10.8 \pm 1.5$ & $11.93 \pm 1.7$ \\
SOD (U/mg) & $1.3 \pm 0.3$ & $1.2 \pm 0.2$ & $1.5 \pm 0.1$ \\
XO (U/mg) & $0.6 \pm 0.09$ & $0.4 \pm 0.04$ & $0.5 \pm 0.04$ \\
Carbonyl residues & $0.15 \pm 0.03$ & $0.17 \pm 0.02$ & $0.15 \pm 0.02$ \\
(nmol/mg) & $0.10 \pm 0.01$ & $0.09 \pm 0.01$ & $0.11 \pm 0.02$ \\
MDA $(\mu \mathrm{M})$ & & &
\end{tabular}

Data are expressed as means \pm S.E.M. $n=5$ in each group.

8-oxodGuo in kidney DNA induced by toxic compounds [33] and the increased excretion of 8-oxodGuo in urine of genetically hypertensive rats [34]. Recently, resveratrol has also been shown to ameliorate hepatic injury in rats with severe acute pancreatitis, suppress oxidative stress and inflammatory response in diethylnitrosamineinitiated rat hepatocarcinogenesis $[9,16]$ and protect PC12 cells against 4-hydroxynonenal induced oxidative stress-mediated apoptotic neurodegeneration [17].

It has been suggested that 2-NP metabolism in the liver does produce a variety of metabolites, including the anionic tautomer propane 2-nitrate, nitric oxide, lipid hydroperoxide radicals and nitrogen dioxide radicals, capable of causing cellular damage [33-35]. In particularly, as we and others reported, 2-NP at dose of 100 $\mathrm{mg} / \mathrm{kg}$ is able to induce a powerful oxidative DNA damage in the rat liver tissue $[18,20,21,36]$. Resveratrol does seem to be able to protect cells against oxidative injury through different mechanisms [37,38]. Leonard et al., [39] have showed that resveratrol did scavenge the $\mathrm{O}_{2}{ }^{-}$ radical produced by cells after exposure to $\mathrm{Cr}(\mathrm{VI})$ and observed an inhibition of DNA damage due to $\mathrm{OH}^{\circ}$ radicals produced by the Fenton reaction [39]. The protective effects of resveratrol on oxidative DNA damage in vivoinduced found in our experiments confirm the radical scavenger ability of resveratrol earlier found in vitro and in ex vivo assays $[40,41]$. In addition, the normalization of XO activity induced by resveratrol in our experiments does suggest that a reduced superoxide generation through XO may explain another mechanism by which resveratrol exercts a protective effect, in line with results previously presented by Ates et al. [42] in traumatic brain injury. We also found that resveratrol tended to normalize the GSH/GSSG ratio which was inversely correlated with the variations of 8-oxodGuo in DNA. This last observation does suggest that the reduction of oxidative DNA damage operated by resveratrol might be possibly due, amongst other causes, to an attenuation of 2-NP-mediated GSH depletion, as reported by Kode et al., [43], who demonstrated that resveratrol does protect against cigarette smoke-mediated oxidative stress in human lung epithelial cells inducing GSH synthesis.

Lipoperoxidation measured as MDA levels, in the liver of rats killed $15 \mathrm{~h}$ after $100 \mathrm{mg} / \mathrm{kg} 2-\mathrm{NP}$, did not undergo any significant change in our experiments. On the contrary, an increase of MDA was reported by Wilhelm in rats who had been administered with 120 $\mathrm{mg} / \mathrm{kg}$ 2-NP. Lipoperoxidation products (MDA + 4-hydroxyalkenals) was found by others in rat liver treated with 2-NP at $165 \mathrm{mg} / \mathrm{kg}$ [44] and at our dose of $100 \mathrm{mg} / \mathrm{kg}$ but measured $48 \mathrm{~h}$ after 2-NP administration [21]. Therefore, the lack of lipoperoxidation in our experiments may have been cause by variations in dose and sampling times. However, in our experiments 2-NP did enhance SOD activity, probably as an antioxidant response. Consequently, lipoperoxidation did not occur, as suggested by the inverse correlation found between MDA and SOD in 2-NP rat group. We suppose that pre-treatment with resveratrol protecting liver by injury it is capable of blocking anti-oxidant defensive response, consequently, SOD activity in 2-NP+Res group is similar to that of controls. Borges et al. [21] did not observe a change in SOD activity in the liver of rats sacrificed $48 \mathrm{~h}$ after 2-NP injection. Once more the difference in lag time might explain such discrepancy. Like change in SOD activity, a tendency $(\mathrm{p}=0.06)$ of increase in the expression of the OGG1 gene, absent in the 2-NP rat group treated with resveratrol, was detected in the liver of 2-NP rats, indicating that 2-NP injection may induce a protective response also through an increasing of DNA repair pathway. Although higher OGG1 gene expression and SOD activity were found in the liver of 2-NP rats than controls, 8-oxodGuo levels were enhanced in their liver DNA. On the contrary, 2-NP+Res rats had 8-oxodGuo levels similar to those found in controls suggesting that resveratrol is capable to reduce oxidation damage 2-NP-induced in the liver DNA. The induction of oxidative DNA damage $15 \mathrm{~h}$ after $100 \mathrm{mg} / \mathrm{kg} 2-\mathrm{NP}$ injection was accompanied with a relevant activation of caspase-3, so informing of an induced apoptosis. Resveratrol at the dose of $50 \mathrm{mg} / \mathrm{kg} /$ day for 14 days before 2-NP injection was able to almost prevent completely $(98 \%)$ the induction of apoptosis and to reduce oxidative DNA damage at levels similar to those detected in the liver of control rats. This observation was consistent with the results obtained by Sha et al., [9] in rats with acute hepatic injury who found that resveratrol $(10 \mathrm{mg} / \mathrm{kg})$, injected through the Vena Dorsalis of the penis ameliorated hepatic injury, via the mitochondrial pathway, in rats with chemically induced acute pancreatitis [9]. Recently, similar observations were reported by Siddiqui $e t$ al., [16] in PC12 cells exposed for $2 \mathrm{~h}$ to 4-hydroxynone- 
nal using resveratrol at $25 \mu \mathrm{M}$ concentration.

Coming to a conclusion, our results prove oxidative DNA damage and apoptosis to be the main mechanisms of death cell in a model of chemically induced acute hepatic injury. At this early stage of damaging processes, resveratrol at dose of $50 \mathrm{mg} / \mathrm{kg}$ /day administered 14 days long can ameliorate hepatic injury by its antioxidant and scavenging properties, through a reduction of $\mathrm{XO}$ activity, a partial restoration of GSH/GSSG ratio in addition to its capacity to inhibit apoptosis.

\section{Acknowledgements}

This work has been receiving financial support from the University of Florence. The authors express their gratitude to Mary Forrest for her linguistic revision.

\section{References}

[1] H. Wei, "Activation of Oncogenes and/or Inactivation of Anti-Oncogenes by Reactive Oxygen Species," Medical Hypotheses, Vol. 39, No. 3, 1992, pp. 267-267. doi:10.1016/0306-9877(92)90120-2

[2] T. Takeuchi and K. Morimoto, "Increased Formation of 8-Hydroxydeoxyguanosine, an Oxidative DNA Damage, in Lymphoblasts from Fanconi's Anemia Patients Due to Possible Catalase Deficiency," Carcinogenesis, Vol. 14, No. 6, 1993, pp. 1115-1120. doi:10.1093/carcin/14.6.1115

[3] R. Shimoda, M. Nagashima, M. Sakamoto, N. Yamaguchi, S. Hirohashi, J. Yokota and H. Kasai, "Increased Formation of Oxidative DNA Damage, 8-Hydroxydeoxyguanosine, in Human Livers with Chronic Hepatitis," Cancer Research, Vol. 54, No. 12, 1994, pp. 3171-3172.

[4] M. B. Reddy and L. Clark, "Iron, Oxidative Stress, and Disease Risk," Nutrition Reviews, Vol. 62, No. 3, 2004, pp. 120-124. doi:10.1301/nr.2004.mar.120-124

[5] A. M. Shah and K. M. Channon, "Free Radicals and Redox Signalling in Cardiovascular Disease," Heart, Vol. 90, No. 5, 2004, pp. 486-487. doi:10.1136/hrt.2003.029389

[6] Y. J. Cai, J. G. Fang, L. P. Ma, L. Yang and Z. L. Liu, "Inhibition of Free Radical-Induced Peroxidation of Rat Liver Microsomes by Resveratrol and Its Analogues," Biochimica et Biophisica Acta, Vol. 1637, No. 1, 2003, pp. 31-38.

[7] A. Cavallaro, T. Ainis, C. Bottari and V. Fimiani, "Effect of Resveratrol on Some Activities of Isolated and in Whole Blood Human Neutrophils," Physiological Research, Vol. 52, No. 5, 2003, pp. 555-562.

[8] G. C. Yen, P. D. Duh and C. W. Lin, "Effects of Resveratrol and 4-Hexylresorcinol on Hydrogen PeroxideInduced Oxidative DNA Damage in Human Lymphocytes," Free Radical Research, Vol. 37, No. 5, 2003, pp. 509-514. doi:10.1080/1071576031000083099

[9] H. Sha, Q. Ma, R. K. Jha, F. Xu, L. Wang, Z. Wang, Y. Zhao and F. Fan, "Resveratrol Ameliorates Hepatic In- jury via the Mitochondrial Pathway in Rats with Severe Acute Pancreatitis," European Journal of Pharmacology, Vol. 601, No. 1-3, 2008, pp. 136-142. doi:10.1016/j.ejphar.2008.10.017

[10] D. Delmas, A. Lançon, D. Colin, B. Jannin and N. Latruffe, "Resveratrol as a Chemopreventive Agent: A Promising Molecule for Fighting Cancer," Current Drug Targets, Vol. 7, No. 4, 2006, pp. 423-442. doi:10.2174/138945006776359331

[11] E. Tili, J. J. Michaille, H. Alder, S. Volinia, D. Delmas, N. Latruffe and C. M. Croce, "Resveratrol Modulates the Levels of microRNAs Targeting Genes Encoding TumorSuppressors and Effectors of TGF $\beta$ Signaling Pathway in SW480 Cells," Biochemical Pharmacology, Vol. 80, No. 12, 2010, pp. 2057-2065. doi:10.1016/j.bcp.2010.07.003

[12] S. Pervaiz, "Chemotherapeutic Potential of the Chemopreventive Phytoalexin Resveratrol," Drug Resistance Updates, Vol. 7, No. 6, 2004, pp. 333-344. doi:10.1016/j.drup.2004.11.001

[13] K. B. Harikumar and B. B. Aggarwal, "Resveratrol: A Multi Targeted Agent or Age-Associated Chronic Diseases," Cell Cycle, Vol. 7, No. 8, 2008, pp. 1020-1035. doi:10.4161/cc.7.8.5740

[14] M. A. Siddiqui, M. P. Kashyap, V. Kumar, A. A. Al-Khedhairy, J. Musarrat and A. B. Pant, "Protective Potential of Trans-Resveratrol against 4-Hydroxynonenal Induced Damage in PC12 Cells," Toxicology in Vitro, Vol. 24, N. 6, 2010, pp. 1592-1598.

doi:10.1016/j.tiv.2010.06.008

[15] T. Tunali-Akbay, O. Sehirli, F. Ercan and G. Sener, "Resveratrol Protects against Methotrexate-Induced Hepatic Injury in Rats," Journal of Pharmacology and Pharmacy Science, Vol. 13, No. 2, 2010, pp. 303-310.

[16] A. Bishayee, K. F. Barnes, D. Bhatia, A. S. Darvesh and R. T. Carroll, "Resveratrol Suppresses Oxidative Stress and Inflammatory Response in Diethylnitrosamine-Initiated Rat Hepatocarcinogenesis," Cancer Prevention and Research, Vol. 3, No. 6, 2010, pp. 753-763. doi:10.1158/1940-6207.CAPR-09-0171

[17] R. Harrison, G. Letz, G. Pasternak and P. Blanc, "Fulminant Hepatic Failure after Occupational Exposure to 2-Nitropropane," Annals of Internal Medicine, Vol. 107, No. 4, 1987, pp. 466-468.

[18] E. S. Fiala, C. C. Conaway and G. E. Mathis, "Oxidative DNA and RNA Damage in the Livers of Sprague-Dawley Rats Treated with the Hepatocarcinogen 2-Nitropropane," Cancer Research, Vol. 49, No. 20, 1989, pp. 5518-5522.

[19] R. S. Sodum, G. Nie and E. S. Fiala, "8-Aminoguanine: A Base Modification Produced in Rat Liver Nucleic Acids by the Hepatocarcinogen 2-Nitropropane," Chemical Research of Toxicology, Vol. 6, No. 3, 1993, pp. 269-276. doi:10.1021/tx00033a004

[20] C. Casalini, M. Lodovici, C. Briani, G. Paganelli, S. Remy, V. Cheynier and P. Dolara, "Effect of COMPLEX polyphenols and Tannins from Red Wine (WCPT) on 
Chemically Induced Oxidative DNA Damage in the Rat," European Journal of Nutrition, Vol. 38, No. 4, 1999, pp. 190-195. doi:10.1007/s003940050061

[21] L. P. Borges, C. W. Nogueira, R. P. Panatieri, J. B. T. Rocha and G. Zeni, "Acute Liver Damage Induced by 2-Nitropropane in Rats: Effect of Diphenyl Diselenide on Antioxidant Defences," Chemico-Biological Interactions, Vol. 160, No. 2, 2006, pp. 99-107.

[22] A. Unnikrishnan, J. J. Raffoul, H. V. Pate, T. M. Prychitko, N. Anyangwe, L. B. Meira, E. C. Friedberg, D. C. Cabelof and A. R. Heydari, "Oxidative Stress Alters Base Excision Repair Pathway and Increases Apoptotic Response in Apurinic/Apyrimidinic Endonuclease 1/Redox Factor-1 Haploinsufficient Mice," Free Radical Biology and Medicine, Vol. 46, No. 11, 2009, pp. 14881499. doi:10.1016/j.freeradbiomed.2009.02.021

[23] L. D. Williams, G. A. Burdock, J. A. Edwards, M. Beck, J. Bausch, L. D. Williams, G. A. Burdock, J. A. Edwards, M. Beck and J. Bausch, "Safety Studies Conducted on High-Purity Trans-Resveratrol in Experimental Animals," Food and Chemical Toxicology, Vol. 47, No. 9, 2009, pp. 2170-2182. doi:10.1016/j.fct.2009.06.002

[24] A. Bishayee, "Cancer Prevention and Treatment with Resveratrol: From Rodent Studies to Clinical Trials," Cancer Prevention Research, Vol. 2, No. 5, 2009, pp. 409-418. doi:10.1158/1940-6207.CAPR-08-0160

[25] C. M. Gedik, A. Collins, ESCODD (European Standards Committee on Oxidative DNA Damage), "Establishing the Background Level of Base Oxidation in Human Lymphocyte DNA: Results of an Interlaboratory Validation Study," FASEB Journal, Vol. 19, No. 1, 2005, pp. 82-84.

[26] M. Lodovici, C. Casalini, R. Cariaggi, L. Michelucci and P. Dolara, "Levels of 8-Hydroxydeoxyguanosine as a Marker of DNA Damage in Human Leukocytes," Free Radical Biology and Medicine, Vol. 28, No. 1, 2000, pp. 13-17. doi:10.1016/S0891-5849(99)00194-X

[27] V. Correa-Salde and I. Albesa, "Reactive Oxidant Species and Oxidation of Protein and Haemoglobin as Biomarkers of Susceptibility to Stress Caused by Chloramphenicol," Biomedical Pharmacotherapy, Vol. 63, No. 2, 2009, pp. 100-104. doi:10.1016/j.biopha.2008.05.001

[28] R. Mateos, E. Lecumberri, S. Ramos, L. Goya and L. Bravo, "Determination of Malondialdehyde (MDA) by High-Performance Liquid Chromatography in Serum and Liver as a Biomarker for Oxidative Stress. Application to a Rat Model for Hypercholesterolemia and Evaluation of the Effect of Diets Rich in Phenolic Antioxidants from Fruits," Journal of Chromatography B-Analytical Technologies in the Biomedical and Life Science, Vol. 827, No. 1, 2005, pp. 76-82.

doi:10.1016/j.jchromb.2005.06.035

[29] C. Beauchamp and I. Fridovich, "Superoxide Dismutase: Improved Assays and an Assay Applicable to Acrylamide Gels," Analytical Biochemistry, Vol. 44, No. 1, 1971, pp. 276-287. doi:10.1016/0003-2697(71)90370-8

[30] E. D. Corte and F. Stirpe, "Regulation of Xanthine Oxidase in Rat Liver: Modifications of the Enzyme Activity of Rat Liver Supernatant on Storage at 20 Degrees," Bio- chemical Journal, Vol. 108, No. 2, 1968, pp. 349-351.

[31] C. Cereser, J. Guichard, J. Drai, E. Bannier, I. Garcia, S. Boget, P. Parvaz and A. Revol, "Quantitation of Reduced and Total Glutathione at the Femtomole Level by High-Performance Liquid Chromatography with Fluorescence Detection: Application to Red Blood Cells and Cultured Fibroblasts," Journal of Chromatography B Biomedical Sciences and Applications, Vol. 752, No. 1, 2001, pp. 123-132.

doi:10.1016/S0378-4347(00)00534-X

[32] C. Luceri, G. Caderni, A. Sanna and P. Dolara, "Red Wine and Black Tea Polyphenols Modulate the Expression of Cycloxygenase-2, Inducible Nitric Oxide Synthase and Glutathione-Related Enzymes in Azoxymethane-Induced $\mathrm{f} 344$ Rat Colon Tumors," Journal of $\mathrm{Nu}$ trition, Vol. 132, No. 6, 2002, pp. 1376-1379.

[33] X. S. Deng, J. Tuo, H. E. Poulsen and S. Loft, "Prevention of Oxidative DNA Damage in Rats by Brussels Sprouts," Free Radical Research, Vol. 28, No. 3, 1998, pp. 323- 333. doi:10.3109/10715769809069284

[34] G. Barja, "Resveratrol, Melatonin, Vitamin E, and PBN Protect against Renal Oxidative DNA Damage Induced by the Kidney Carcinogen $\mathrm{KBrO}_{3}$," Free Radical Biology and Medicine, Vol. 26, No. 11-12, 1999, pp. 1531-1534. doi:10.1016/S0891-5849(99)00019-2

[35] K. Mizutani, K. Ikeda, Y. Kawai and Y. Yamori," Protective Effect of Resveratrol on Oxidative Damage in Male and Female Stroke-Prone Spontaneously Hypertensive Rats," Clinical and Experimental Pharmacology and Physiology, Vol. 28, No. 1-2, 2001, pp. 55-59. doi:10.1046/j.1440-1681.2001.03415.x

[36] B. Halliwell and J. M. Gutteridge, "Role of Free Radicals and Catalytic Metal Ions in Human Disease: An Overview," Methods in Enzymology, Vol. 186, 1990, pp. 1-85. doi:10.1016/0076-6879(90)86093-B

[37] W. Bors, C. Michel, C. Dalke, K. Stettmaier, M. Saran and U. Andrae, "Radical Intermediates during the Oxidation of Nitropropanes. The Formation of $\mathrm{NO}_{2}$ from 2-Nitropropane, Its Reactivity with Nucleosides, and Implications for the Genotoxicity of 2-Nitropropane," Chemical Research in Toxicology, Vol. 6, No. 3, 1993, pp. 302-309. doi:10.1021/tx00033a008

[38] C. Kohl, P. Morgan and A. Gescher, "Metabolism of the Genotoxicant 2-Nitropropane to a Nitric Oxide Species," Chemico-Biological Interactions, Vol. 97, No. 2, 1995, pp. 185-194.

[39] S. S. Leonard, C. Xia, B. H. Jiang, B. Stinefelt, H. Klandorf, G. K. Harris and X. Shi, "Resveratrol Scavenges Reactive Oxygen Species and Effects Radical-Induced Cellular Responses," Biochemical and Biophysical Research Communications, Vol. 309, No. 4, 2003, pp. 10171026. doi:10.1016/j.bbrc.2003.08.105

[40] S. Bradamante, L. Barenghi and A. Villa, "Cardiovascular Protective Effects of Resveratrol," Cardiovascular and Drug Reviews, Vol. 22, No. 3, 2004, pp. 169-188.

[41] P. S. Ray, G. Maulik, G. A. Cordis, A. A. Bertelli, A. Bertelli and D. K. Das, "The Red Wine Antioxidant Res- 
veratrol Protects Isolated Rat Hearts from Ischemia Reperfusion Injury," Free Radical Biology and Medicine, Vol. 27, No. 1-2, 1999, pp. 160-169. doi:10.1016/S0891-5849(99)00063-5

[42] O. Ates, S. Cayli, E. Altinoz, I. Gurses, N. Yucel, M. Sener, A. Kocak and S. Yologlu, "Neuroprotection by Resveratrol against Traumatic Brain Injury in Rats," Molecular and Cellular Biochemistry, Vol. 294, No. 1-2, 2007, pp. 137-144. doi:10.1007/s11010-006-9253-0

[43] A. Kode, S. Rajendrasozhan, S. Caito, S. R. Yang, I. L. Megson and I. Rahman, "Resveratrol Induces Glutathione
Synthesis by Activation of Nrf2 and Protects against Cigarette Smoke-Mediated Oxidative Stress in Human Lung Epithelial Cells," American Journal of Physiological Lung Cellular and Molecular Physiology, Vol. 294, No. 3, 2008, pp. L478-L488. doi:10.1152/ajplung.00361.2007

[44] S. J. Kim, R. J. Reiter, M. V. Rouvier Garay, W. Qi, G. H. El-Sokkary and D. X. Tan, "2-Nitropropane-Induced Lipid Peroxidation: Antitoxic Effects of Melatonin," Toxicology, Vol. 130, No. 2-3, 1998, pp. 183-190. doi:10.1016/S0300-483X(98)00111-5 